\title{
ENHANCEMENT OF HEAT TRANSFER FROM PLATE FIN HEAT SINKS
}

\author{
S.D.Ratnakar ${ }^{1}$, D.D.Palande ${ }^{2}$ \\ ${ }^{1}$ Mechanical Department, M.C.O.E\&RC, Nasik, India - 4220105 \\ ${ }^{2}$ Mechanical Department, M.C.O.E\&RC, Nasik, India - 4220105
}

\begin{abstract}
Heat Sinks are an extremely useful component used to lower the maximum temperature of various electronic devices during operation so as to increase their thermal efficiency and performance. Fins constitute an important and integral component of sinks. It is a passive cooling technique. Plate fin heat sinks are used in varied applications owing to its low manufacturing cost, ease of manufacture and its economical way to dissipate unwanted heat. Steady state natural convection is experimentally investigated for 03 sets of vertically mounted fin heat sinks. Aluminum is used because of its high conductivity. Length and fin thickness is kept constant at $200 \mathrm{~mm}$ and $05 \mathrm{~mm}$ respectively. Fin height is successively increased as 10mm, 30mm, 50mm.Aspect Ratio for above three sets is thus 0.05, 0.15 and 0.25 respectively. Effect of varying height, heat input and aspect ratio, keeping length constant is investigated on heat transfer through the sinks.
\end{abstract}

Keywords: Heat Sinks, Fins, Natural Convection, Aspect Ratio.

****

\section{ABBREVIATIONS AND SYMBOLS}

h - Convection heat transfer coefficient, W/ $\left(\mathrm{m}^{2} \mathrm{~K}\right)$

A - Area, $\mathrm{m}^{2}$

$\mathrm{Nu} \quad$-Nusselt number

Gr -Grashof number

$\mathrm{S} \quad$ - Fin spacing

$\mathrm{H} \quad$-Fin height, $\mathrm{mm}$

$\mathrm{N} \quad-$ Number of fins

L - Fin length, mm

W - Fin width, mm

$\mathrm{T}$ - Fin thickness, mm

Sopt - Optimum fin spacing, mm

Ra - Rayleigh number

Qin - Power supplied to heater base plate, W

Qc - Total convection heat transfer rate from fins, W

$\mathrm{T}_{\mathrm{avg}} \quad$ - Average base plate temperature, ${ }^{0} \mathrm{C}$

$\mathrm{T}_{\mathrm{amb}} \quad$ - Ambient temperature, ${ }^{0} \mathrm{C}$

$\mathrm{T}$ - Temperature, ${ }^{0} \mathrm{C}$

$\Delta \mathrm{T}$ - Base-to-ambient temperature difference, ${ }^{0} \mathrm{C}$

Tf - Film temperature, ${ }^{0} \mathrm{C}$

$\mathrm{k}$ - Thermal conductivity, W/ (m K)

g - Gravitational acceleration, $\mathrm{m} / \mathrm{s}^{2}$

$\beta$ - Volumetric thermal expansion coefficient, $1 / \mathrm{K}$

$\sigma \quad$ - Stefan-Boltzmann constant, W/ $\left(\mathrm{m}^{2} \mathrm{~K}^{4}\right)$

$v \quad$ - Kinematic viscosity, $\mathrm{m}^{2} / \mathrm{s}$

$\alpha \quad-$ Thermal diffusivity, $\mathrm{m}^{2} / \mathrm{s}$

$\varepsilon \quad-$ Emissivity

Set A - $(\mathrm{L}=200 \mathrm{~mm}, \mathrm{H}=10 \mathrm{~mm})$

Set B - $(\mathrm{L}=200 \mathrm{~mm}, \mathrm{H}=30 \mathrm{~mm})$

Set C - $(\mathrm{L}=200 \mathrm{~mm}, \mathrm{H}=50 \mathrm{~mm})$

\section{INTRODUCTION}

Heat sink is an object that absorbs and dissipates heat from another object by thermal contact. Heat sinks find use in wide range of applications, providing efficient heat dissipation. Some applications include cooling of electronic devices, lasers, heat engines and refrigeration. Thermal energy transfer between two objects rapidly brings first object into thermal equilibrium with second lowering temperature of first object thus accomplishing heat sinks role as a cooling device. If temperature limits exceed a certain value in above applications it may even lead to total system failure. Therefore different methods are used by engineering systems so as to minimize this overheating problem as much as possible. Fins form one of the easiest and cheapest ways to dissipate this heat. Owing to low production costs and high effectiveness, rectangular fins are the most popular fin type. Vertical orientation of fins is widely used from a combination of horizontal and vertical orientation as it is highly effective. Heat dissipation from fins to surroundings takes place by two modes convection and radiation. As aluminium is used for fins, it has low emissivity value hence radiation heat transfer value is low. So convection heat transfer is dominant mode of heat transfer from fins. Heat transfer coefficient and surface area of fins are two important parameters on which rate of heat dissipation depends. Fluid can be forced to flow over fins by fans and in this manner heat transfer coefficient ' $h$ ' can be increased. But it is costly and requires more volume to include fan. Surface area can be increased by addition of more fins. But distance between adjacent fins reduces due to addition of more fins. This may result in offering resistance to air flow thereby reducing heat transfer coefficient. 


\section{EXPERIMENTATION}

Main components include channel, concrete block, base plate, fin array, plate heater and power mains. Aerated concrete block 250x200x100 mm, is fixed on frame which ensures one dimensional heat dissipation. A removable acrylic sheet is placed on front surface to replace fin arrays. Base thickness of arrays is kept as $05 \mathrm{~mm}$. The heater consists of nichrome wire wound around thin mica plate and mica sheet. Rating of heater plate is $250 \mathrm{~W}$ and $230 \mathrm{~V}$, AC.05 mm depth is provided on aerated concrete block to include heater plate. Extruded surface is kept over fin array for fitting to aerated concrete block. Concrete block has inbuilt 04 bolts to tighten fin array over heater plate Thus air gap between fin array and heater plate is considered to be negligible. A concrete block has high insulation quality and temperature resistance. $(\mathrm{K} \approx 0.15 \mathrm{~W} / \mathrm{m} \mathrm{k})$.

Table -1: Set-up Dimensions

\begin{tabular}{|l|l|l|}
\hline Sr.No & Component & Dimensions $(\mathrm{mm})$ \\
\hline 1 & Frame Channel & $550 \times 550 \times 550$ \\
\hline 2 & Heater & $180 \times 200 \times 5$ \\
\hline 3 & Concrete & $250 \times 200 \times 100$ \\
\hline
\end{tabular}

Fin configurations are produced on D.R.O milling. The fin arrays are produced from rectangular bars with dimensions 180x200x60 mm. Fins are integral with base plate of thickness $05 \mathrm{~mm}$ and fin thickness is kept constant at $05 \mathrm{~mm}$.

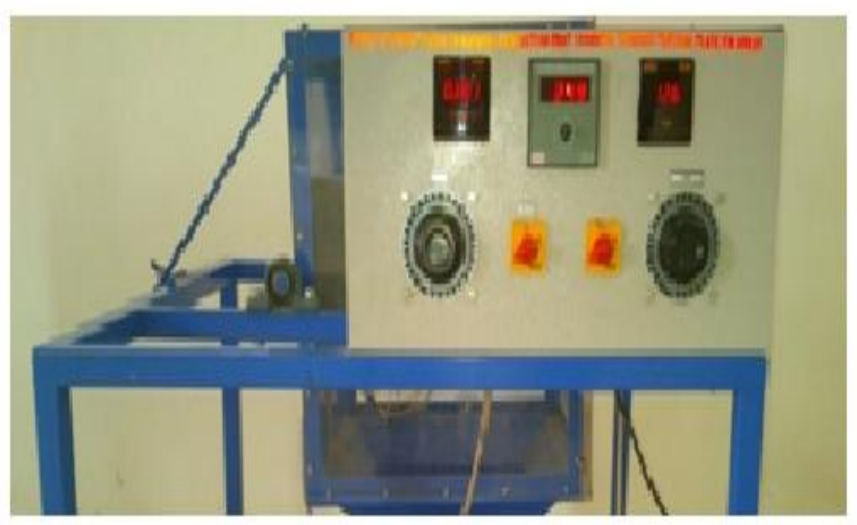

Fig -1: Experimental Set-up

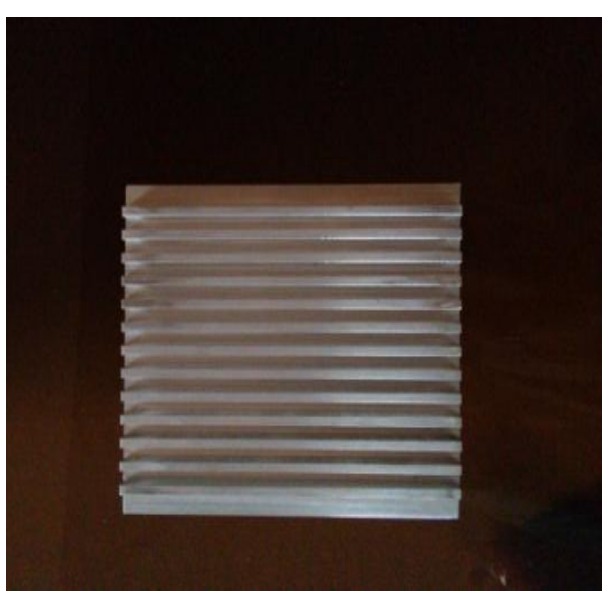

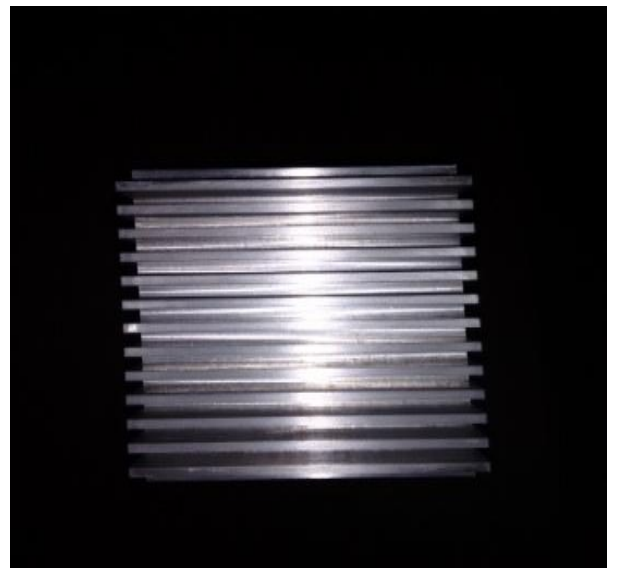

Fig -2: Fin Arrays

The fin array specifications are given in the following table

Table 2: Fin Specifications

\begin{tabular}{|l|l|l|l|l|}
\hline $\begin{array}{l}\text { Sr. } \\
\text { No. }\end{array}$ & $\begin{array}{l}\text { Fin } \\
\text { Length } \\
(\mathrm{mm})\end{array}$ & $\begin{array}{l}\text { Fin } \\
\text { Width } \\
(\mathrm{mm})\end{array}$ & $\begin{array}{l}\text { Fin } \\
\text { Thickness } \\
(\mathrm{mm})\end{array}$ & $\begin{array}{l}\text { Fin Height } \\
(\mathrm{mm})\end{array}$ \\
\hline 1 & 200 & 180 & 05 & 10 \\
\hline 2 & 200 & 180 & 05 & 30 \\
\hline 3 & 200 & 180 & 05 & 50 \\
\hline
\end{tabular}

\section{EQUATIONS}

(1) Heat Loss by Convection, Qc:

$\mathrm{Qc}=($ heater input $)-($ heat loss by radiation, $\mathrm{Qr})$

$$
\begin{gathered}
\mathrm{Qc}=\mathrm{h} \mathrm{A} \Delta \mathrm{T} . \\
\mathrm{Qr}=\varepsilon \sigma \mathrm{A}_{\mathrm{t}}\left(\mathrm{T}_{\mathrm{avg}}{ }^{4}-\mathrm{T}_{\mathrm{amb}}{ }^{4}\right)
\end{gathered}
$$

(2).Average Heat Transfer Coefficient.

$$
\mathrm{h}_{\mathrm{avg}}=\mathrm{Qc} /(\mathrm{A} \Delta \mathrm{T})
$$

(3)Mean Film Temperature:

$$
\mathrm{Tf}=\left(\mathrm{T}_{\mathrm{avg}}+\mathrm{T}_{\mathrm{amb}}\right) / 2
$$

(4)Experimental Nusselt Number:

$$
\begin{gathered}
\mathrm{Nu}_{\text {exp }}=\left(\mathrm{h}_{\mathrm{avg}} \mathrm{L}\right) / \mathrm{K} \\
\mathrm{Ra}=\left\{\mathrm{g} \beta \mathrm{L}^{3}\left(\mathrm{~T}_{\mathrm{avg}}-\mathrm{T}_{\mathrm{amb}}\right)\right\} /(\alpha v) .
\end{gathered}
$$

\section{EXPERIMENTAL PROCEDURE}

Heat inputs can be adjusted by a dimmer stat. The temperature of heat sink at different locations and ambient temperatures are recorded at time interval of 30 minutes till steady state is reached. Generally it takes around $02 \mathrm{hrs}$ to attain steady state condition. Temperature variation of around $0.5^{\circ} \mathrm{C}$ is taken for steady state approximation. Six thermocouples are used. Five of them are attached to the base and one is kept suspended inside the channel to record ambient temperature. 
Parameters used for study are as follows:

$\begin{array}{ll}\text { Heat Input (Qin) } & : 20 \mathrm{~W}, 40 \mathrm{~W}, 60 \mathrm{~W}, 80 \mathrm{~W}, 100 \mathrm{~W} \\ \text { Base Temperature } & : \mathrm{T}_{1}, \mathrm{~T}_{2}, \mathrm{~T}_{3}, \mathrm{~T}_{4}, \mathrm{~T}_{5} \\ \text { Ambient Temperature } & : \mathrm{T}_{6}\end{array}$

\section{EMPIRICAL CORELATIONS}

Empirical relations are used to validate the vertical orientation model. Following correlations are considered:

(1)Mc Adam's correlation:

$$
\mathrm{Nu}=0.59 \times R a^{0.25}
$$

(2)Churchill and Chu's first correlation:

$$
\mathrm{Nu}=\left[0.825+\frac{0.387 \times R a^{1 / 6}}{\left[1+\left(\frac{0.492}{P r}\right)^{9 / 16}\right]^{8 / 27}}\right]^{2}
$$

(3)Churchill and Chu's Second correlation:

$$
\mathrm{Nu}=0.68+\frac{0.67 \times \mathrm{Ra}^{1 / 4}}{\left[1+\left(\frac{0.492}{P r}\right)^{0 / 16}\right]^{4 / 2}}
$$

(4)Churchill and Usagi's correlation:

$$
\mathrm{Nu}=\frac{0.67 \times R a^{1 / 4}}{\left[1+\left(\frac{0.492}{P_{Y}}\right)^{9 / 16}\right]^{4 / 9}}
$$

\section{RESULT ANALYSIS}

\subsection{Variation of Nusselt Number with Different Power Input}

Figure3 shows variation of Nusselt No. With different power input for arrays. Figure shows experimental Nusselt Number with that of calculated from various existing Equations. Value of $\mathrm{Nu}$ number from experimentation is close to that of from existing equations. Three sets are plotted for $10,30,50 \mathrm{~mm}$ height and length of $200 \mathrm{~mm}$.

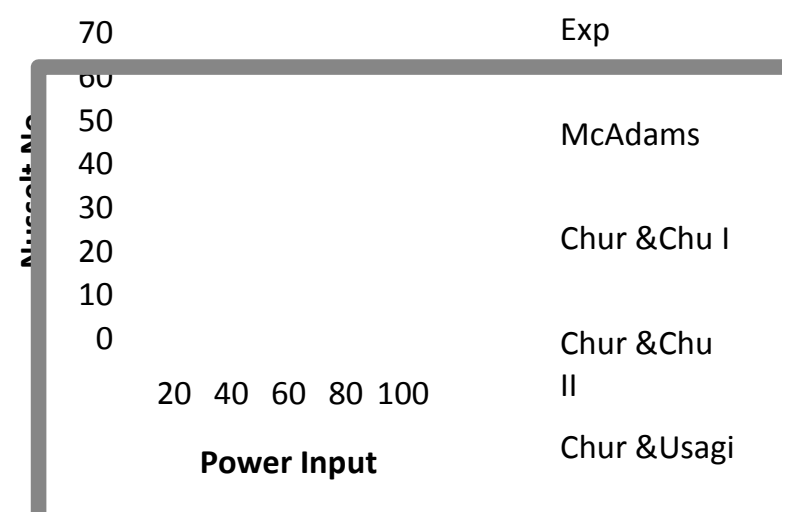

Chart -1: Nusselt Vs Input Power Set A

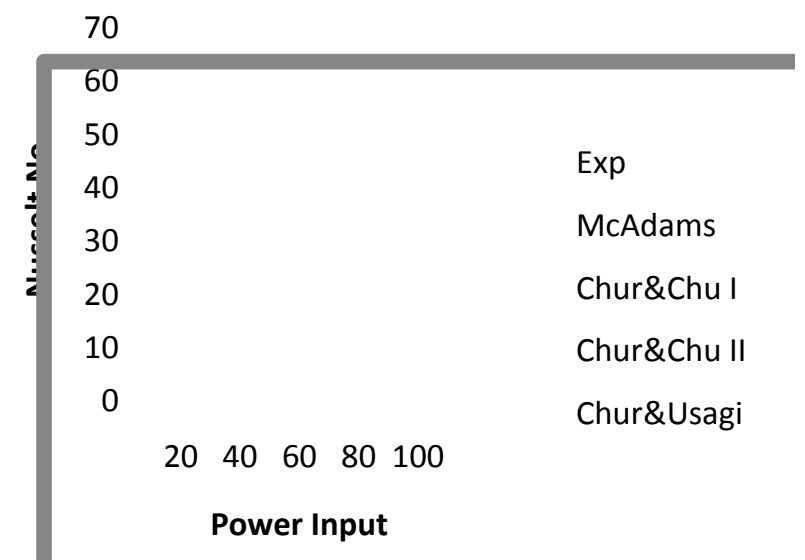

Chart -2: Nusselt Vs Input Power SetB

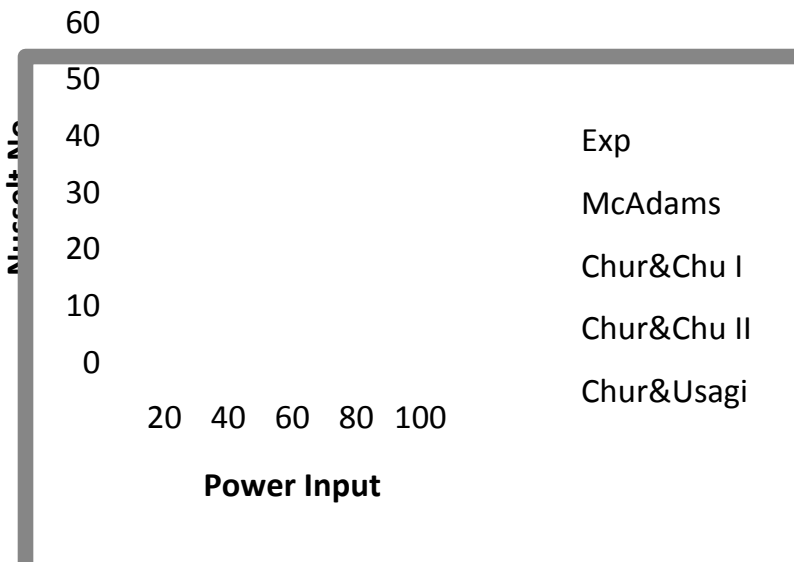

Chart -3: Nusselt Vs Input Power Set C

\subsection{Variation of Convective Heat Transfer with}

\section{Different Power Input for Different Fin arrays}

Figure 4 shows variation of convective heat transfer with different power input for various fin arrays. As power input increases ' $h$ ' increases for all arrays. Convective heat transfer ' $h$ ' is more for arrays with small height when length and input power is constant.

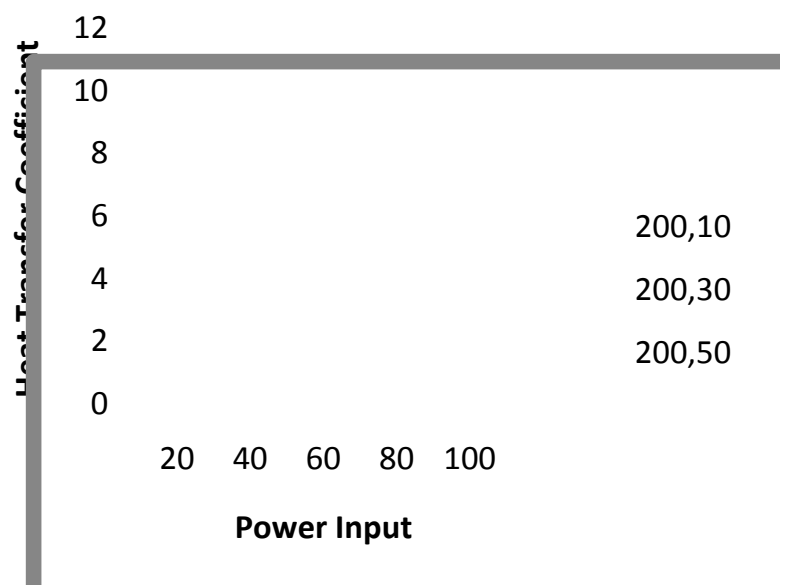

Chart -4: Heat Coefficient Vs Input Power 


\subsection{Variation of Convective Heat Transfer Rate with Fin Height for Different Power Input}

Convective heat transfer rate from fin arrays increases with an increase in fin height. As fin height increases total heat dissipation area also increases. Convective heat transfer rate is directly related to surface area in contact with air

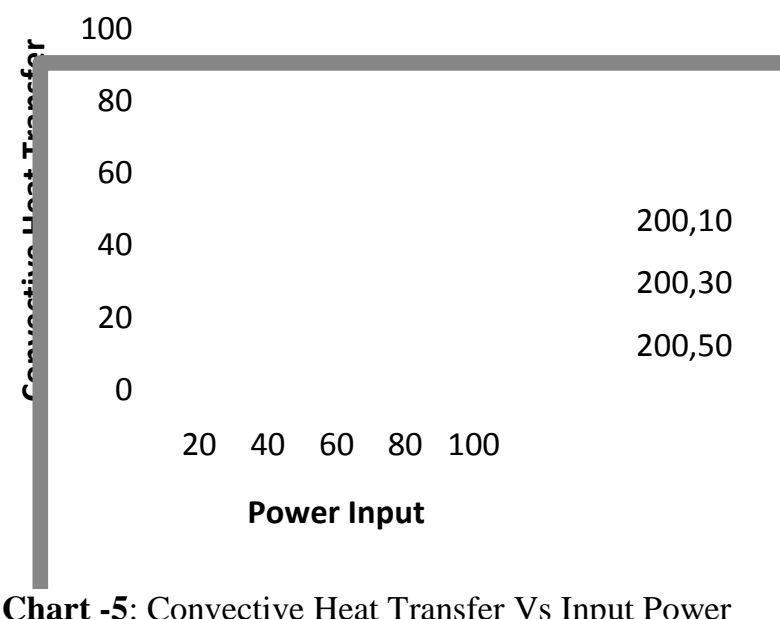

Chart -5: Convective Heat Transfer Vs Input Power

\section{CONCLUSION}

- Natural convective heat transfer depends on fin height.

- Convective heat transfer rate from fins increases with an increase in height of fin arrays.

- Experimental Nusselt Number is quite close to the value obtained from correlation

- With an increase in heat input and temperature difference, natural convective heat transfer also increases.

- With an increase in heat input, heat transfer by radiation mode also correspondingly increases.

- Convective heat transfer increases with aspect ratio for given power input.

\section{REFERENCES}

[1]. Kamal-Eldin Hassan and Salah A. Mohamed, Natural Convection from Isothermal Flat Surfaces, ht. J. Heat Mass Transfer. 1970 Vol. 13, pp. 1873-1886. Pergamon Press.

[2]. E. M. Sd L. F. A. Azevedo, Vertical-Channel Natural Convection Spanning Between the Fully-Developed Limit and The Single-Plate Boundary-Layer Limit, Int. Journal Heat Mass Transfer. 1985Vol. 28, No. 10, pp. 1847-1857

[3]. Burak yazicioğlu and Hafit Yüncü, A Correlation for Optimum Fin Spacing of Vertically-Based Rectangular Fin Arrays Subjected to Natural Convection Heat Transfer, J. of Thermal Science and Technology, 2009, ISSN 1300-3615 29, 1, 99-105

[4]. Mehdi Mehrtash, Ilker Tari, A Correlation for Natural Convection Heat Transfer from Inclined Plate-finned Heat Sinks, Applied Thermal Engineering 512013 1067-1075. [5]. F.P.Incropera, D.P. DeWitt, Fundamentals of Heat and Mass Transfer John Wiley \& Sons, New York, 1990.
[6]. Y.A.Cengel, Heat and Mass Transfer Tata McGraw Hill, 2007.

[7]. Burak Yazicioğlu.,Performance of Rectangular Fins on a Vertical Base in Free Convection Heat Transfer, M.S. Thesis in Mechanical Engineering, Middle East Technical University, Ankara2005.

[8]. Kamil Mert Çakar Numerical Investigation of Natural Convection from Vertical Plate Finned Heat Sinks Middle East Technical University, June 2009.

\section{BIOGRAPHY}

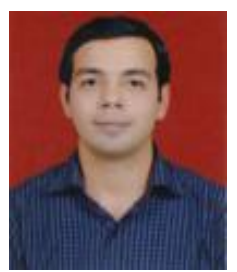

Swapnil Dipak Ratnakar, Completed B.E Mechanical from SVIT, Chincholi.Presently pursuing M.E Heat Power from Matoshri College of Engineering and Research, Nasik. 